\title{
EI ascenso a la superficie: Eurídice en The World's Wife de Carol Ann Duffy y Retrato de una mujer en llamas de Céline Sciamma
}

\author{
The Ascent to the Surface: Eurydice in Carol Ann Duffy's \\ The World's Wife and Céline Sciamma's \\ Portrait of a Lady on Fire
}

\author{
Julieta FLORES JURAdO \\ Facultad de Filosofía y Letras \\ Universidad Nacional Autónoma de México | México \\ Contacto: julietafloresjurado@filos.unam.mx
}

\section{Resumen}

Este artículo compara dos lecturas contemporáneas de la figura de Eurídice: el poema "Eurydice", parte de la colección The World's Wife de Carol Ann Duffy, y la película Retrato de una mujer en llamas, dirigida por Céline Sciamma. Lejos de limitarse a narrar el mito desde una perspectiva femenina, el trabajo que Duffy y Sciamma realizan supone una reflexión sobre las resonancias actuales de esta historia, en especial sobre la necesidad de que las experiencias de las mujeres puedan representarse bajo sus propios términos, tanto en la literatura como en el cine. Para sustentar este argumento, ambas obras se concentran en la mirada y la creación de imágenes como actos de poder y pronuncian fallidas aquellas representaciones que omiten la aportación de las mujeres que posan. Además de comentar las conexiones y los contrastes entre la poesía de Duffy y la película dirigida por Sciamma, este trabajo concuerda con el entendimiento de Sciamma del cine como colaboración, con su rechazo a la figura de la musa, y su deseo de narrar una historia de amor basada en el consentimiento y la equidad. Por último, sostengo que en la obra posterior de Duffy, específicamente en los sonetos amatorios de su poemario Rapture, se encuentra una propuesta comparable: transformar la lírica para poder representar una relación amorosa entre iguales.

Palabras clave: reescritura, intertextualidad, mirada femenina, Eurídice, Carol Ann Duffy, Céline Sciamma, Retrato de una mujer en llamas

\begin{abstract}
This paper draws a comparison between two contemporary readings of the mythical character Eurydice: the poem "Eurydice", from Carol Ann Duffy's The World's Wife, and the film Portrait of a Lady on Fire, directed by Céline Sciamma. Far from merely narrating the myth from a female point of view, the works by Duffy and Sciamma involve a rethinking of the story's current resonances - particularly, the need for women to represent themselves under their own terms both in literature and film. To support this argument, both works center on the gaze and the creation of images as acts of power. By giving voice to those who have frequently been silenced, Duffy and Sciamma argue that representations that do not consider the creative contribution of women who pose will ultimately fail. Besides looking at the links and contrasts between Duffy's poetry and Sciamma's film, this paper follows Sciamma's understanding of filmmaking as collaboration, her rejection of the figure of the muse, and her desire to narrate a love story based on consent and equality. To conclude, I argue that Duffy's later poems, specifically the love sonnets from her collection Rapture, continue this endeavor of enabling the representation of love between equals in the lyric.
\end{abstract}

Keywords: rewriting, intertextuality, female gaze, Eurydice, Carol Ann Duffy, Céline Sciamma, Portrait of a Lady on Fire 
They took the upward path, through the still silence, steep and dark, shadowy with dense fog, drawing near to the threshold of the upper world. Afraid she was no longer there, and eager to see her, the lover turned his eyes. In an instant she dropped back, and he, unhappy man, stretching out his arms to hold her and be held, clutched at nothing but the receding air. Dying a second time, now, there was no complaint to her husband (what, then, could she complain of, except that she had been loved?). She spoke a last "farewell" that, now, scarcely reached his ears, and turned again towards that same place.

-Ovidio, Metamorfosis, Libro X. Traducción de A. S. Kline.

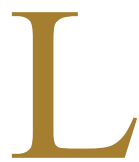

amentando la escasez de tramas disponibles para los personajes femeninos, en 1972 Joanna Russ (1995) afirmó que había un solo tipo de relato en el que una heroína podía destacar: las mujeres sólo eran protagonistas de historias de amor. Aunque irónica en el contexto del ensayo de Russ, una afirmación como ésta hoy puede ser fácilmente desafiada con ejemplos de narraciones centradas en personajes femeninos complejos, cuyas trayectorias en modo alguno se reducen a la búsqueda de la felicidad en una relación amorosa. No obstante, en los últimos años, algunas mujeres creadoras, como Phoebe Waller-Bridge en el teatro y la televisión (Fleabag), o Sally Rooney en la novela (Normal People), se han dedicado a analizar en forma crítica a qué llamamos una historia de amor, y qué estructuras de poder intervienen en cómo los seres humanos experimentan un afecto que suele pretenderse puro, individual e inconfundible. Las historias contadas por Rooney y Waller-Bridge ocurren en el presente. Sin embargo, esta perspectiva crítica también ha conducido a poetas y cineastas a demostrar que las grandes narrativas de amor del pasado no son necesariamente universales; más aún, considero que en su relectura de historias antiguas también surgen preguntas acerca de si es válido llamarle "amor" a uniones a las que una de las dos partes ingresa en clara desventaja. ¿Quién puede ser reconocido como sujeto que ama y desea? ¿Toda declaración de amor debería ser bienvenida? ¿Qué modelos han influido en la forma contemporánea de narrar e interpretar historias de amor?

Estas preguntas son ejes importantes en las dos obras que comentaré a continuación: el poema "Eurydice", de Carol Ann Duffy, y Retrato de una mujer en llamas, película escrita y dirigida por Céline Sciamma. ${ }^{1}$ Consideraré dos aspectos en común: primero, su conciencia de cómo el acto de mirar refleja y a la vez establece relaciones de poder. Algunos modos de ver evidencian una asimetría entre quien mira y quien es mirada: ésta es una distinción que se ha expresado mediante los términos "look" y "gaze" (Richardson,

\footnotetext{
1 El título en la lengua original es Portrait de la jeune fille en feu. En las páginas restantes, usaré el título en español,
} pero las citas de los diálogos se conservan en francés. 
2016: 4): "to look" es una mirada neutral, mientras que "to gaze" es una forma de disciplina y subordinación, el acto que Michel Foucault consideró fundamental en su teoría sobre el panoptismo y que se asocia con adjetivos que indican esta relación desigual, como "male gaze" o "colonial gaze". No obstante, otras perspectivas, como la de W. J. T. Mitchell (2005), argumentan que ninguna mirada puede considerarse totalmente neutral. La visión no ocurre en formas autoevidentes o directas: como todos los sentidos, "[it] is learned and cultivated, not simply given by nature [...] it is deeply involved with human societies, with the ethics and politics, aesthetics and epistemology of seeing and being seen" (Mitchell, 2005: 337). Esta idea de una visión mediada por la cultura, que refleja y produce estructuras sociales, debe conectarse también con el pensamiento feminista, de acuerdo con Amelia Jones (2003): "Feminism has long acknowledged that visuality (the conditions of how we see and make meaning of what we see) is one of the key models by which gender is culturally inscribed in Western culture" (1). Dicho de otra forma, las imágenes están involucradas en la reproducción de un sistema de sexogénero y en procurar la aceptación de la heteronormatividad. La relación que deseo establecer entre "Eurydice" y Retrato de una mujer en llamas consiste en interpretar estos textos como respuestas críticas ante "the powerful association between looking and the exercise of specifically male power" (Loizeaux, 2008: 81). Además de esto, me interesa comparar las formas en que Duffy y Sciamma redistribuyen este poder entre personajes femeninos que, tanto por medios visuales como verbales, consiguen asumir un papel activo en la representación.

El segundo aspecto que enlaza ambas obras es su retorno a un texto clásico leído en formas subversivas y reescrito para adquirir nuevos significados. La poeta escocesa Carol Ann Duffy y la cineasta francesa Céline Sciamma toman como punto de partida la obra que, según la clasicista Mary Beard (2014), es "the most influential work of literature on Western art after the Bible" (s. p.): las Metamorfosis de Ovidio. Específicamente, ambas creadoras llevan a cabo reescrituras feministas del mito de Eurídice y Orfeo, un relato que, de acuerdo con Sciamma, "[is] basically about how the male gaze can kill you" (citada en VanDerWerff, 2020: s. p.). En el poema homónimo, Duffy recrea la voz de Eurídice para rechazar un tipo de representación posesiva que reduce a las mujeres a objetos de deseo diseñados para engrandecer al poeta. Si bien otras autoras han contado el mito desde la perspectiva de Eurídice -la poeta estadounidense H. D. (1916), en un poema también titulado "Eurydice", se concentra en la decepción y el enojo del personaje ante la arrogancia que llevó a Orfeo a romper su promesa-, la versión de Duffy se distingue por el humor y por situar la narración ante una audiencia femenina cómplice, que escucha el relato de los hechos "como en verdad sucedieron". En contraste, la propuesta de Sciamma es una reescritura queer ambientada en una casa remota en la costa de la Bretaña francesa 
durante el siglo XVIII. Retrato de una mujer en llamas narra una relación amorosa entre dos mujeres, Marianne y Héloïse, que transforman sus roles iniciales de retratista y retratada. A pesar de que su tiempo juntas es breve y es imposible extenderlo, Sciamma también resalta el papel de la mirada y la creación de imágenes en relación con la memoria. La película contempla la agencia creativa de las mujeres como hacedoras de imágenes en todos los niveles: en una proyección comentada en el Festival de Cine de Toronto (TIFF), Sciamma se refiere a las actrices principales, Adèle Haenel y Noémie Merlant, como sus colaboradoras, rechaza la noción de "musa" al considerarlo un concepto que invisibiliza la participación de las mujeres en el arte, y afirma que, durante la filmación, "the politic of the set was that there is no muse" (TIFF Talks, 2019: 14:21).

En la historia que se narra en Retrato de una mujer en llamas, Marianne es la pintora profesional, pero Héloïse consigue afirmarse como co-creadora del retrato, mientras que Sophie, la criada, trabaja en un bordado. Fuera del universo ficcional de la película, la pintora Hélène Delmaire es la autora de los cuadros que aparecen en la película, Claire Mathon está a cargo de la fotografía, y finalmente Sciamma es responsable del guion y de la dirección. Se trata, en palabras de Sciamma, de "a manifesto about the female gaze" (citada en Syme, 2020: s. p.). Aunque el título alude a una "mujer en llamas", Sciamma define la película como "a portrait of a woman at work" (TIFF Talks, 2019: 07:15). Además de las correspondencias mencionadas hasta aquí, la idea del manifiesto resulta útil para realizar una comparación no sólo desde una perspectiva tematológica, sino considerando ambas obras como la expresión de una poética, una declaración de los principios estéticos y políticos que ambas creadoras ("women at work") toman como punto de partida. La película, además, invita a considerar el encuentro entre numerosos medios de creación artística: un mito acerca de un poeta influye en las representaciones pictóricas, y esta historia se cuenta en el medio cinematográfico por medio de actuaciones, palabras, imágenes y sonidos. Al final de este artículo propongo que ambas obras resaltan la importancia del consentimiento tanto en el plano afectivo como en el proceso de representar.

Una motivación frecuente de las reescrituras de mitos, relatos históricos y cuentos de hadas es el deseo de multiplicar las perspectivas, de resignificar y recontextualizar eventos y personajes conocidos por un público lector/espectador amplio. Aunque en épocas recientes se han planteado críticas válidas a los numerosos libros y películas que sólo cambian el género del protagonista de una historia previa (por ejemplo, que desplazan aquellas narrativas concebidas con una perspectiva femenina desde un inicio, o que producen la ilusión de una cultura más incluyente de lo que en realidad es), considero que obras como las de Duffy y Sciamma no pretenden simplemente que el texto clásico adquiera nueva relevancia con un cambio de perspectiva, ni hacer de los 
“personajes femeninos fuertes" un fin en sí mismo. Más bien, las creadoras reviven el mito de Eurídice por su idoneidad para explorar preocupaciones actuales sobre el acceso desigual al poder de contar historias en sus respectivos campos. En la proyección que mencioné antes, Sciamma nos recuerda que, aunque Retrato de una mujer en llamas narra una historia situada en el siglo XVIII, la película es contemporánea (TIFF Talks, 2019: 07:25). Considerando esto, me parece adecuado relacionar estos dos ejemplos con los comentarios de Elizabeth Wanning Harries (2015) en "Changing the Story: Fairy Tale, Fantasy, Myth":

writing from another angle $[\ldots]$ has become the dominant way women writers respond to old, familiar stories. They change the subject. They tease new versions out of the gaps in older versions, or sometimes out of the inconsistencies between them. The crucial "irony" comes from the friction between familiar versions of the tales and writers' new angles on them. (161)

Harries propone aproximarse a estas reescrituras desde la noción del palimpsesto: los textos contemporáneos dejan ver las marcas de otros textos sobre los que se encuentran superpuestos, y el propósito de la nueva versión no es cancelar u ocultar la anterior, sino arrojar luz sobre aspectos de la historia que se han pasado por alto. Los mitos y los cuentos de hadas son un punto de referencia y un campo que provee un vocabulario compartido a numerosos/as lectores/as, y sobre esta base, "[w] women writers have often interrupted or questioned gendered patterns that seem immutable (the obedient heroine, the girl and the threatening beast, the 'happily ever after' ending)" (Harries, 2015: 159).

\section{"The dead are so talented"}

Carol Ann Duffy, poeta nacida en Glasgow, Escocia, en 1955, es conocida por ser, hasta hoy, la única mujer y autora queer que ha ocupado el cargo de Poeta Laureada del Reino Unido. La adaptación, la reescritura y el retorno a cuentos de hadas y mitos de siglos pasados son frecuentes en su trayectoria: en 1994 preparó junto con Jim Supple versiones teatrales de los cuentos editados por los Hermanos Grimm, y en 2015 creó una versión moderna de la morality play medieval Everyman, en la que Dios se representa como una mujer que trapea el escenario. En la colección de poemas The World's Wife, publicada en 1999, Duffy centra su atención en las esposas o compañeras de los hombres famosos de la mitología, la historia y la cultura popular. Los poemas son monólogos dramáticos y el título de cada uno anuncia a la voz poética; esta 
reconstrucción de las voces de los personajes femeninos ejemplifica las posibilidades de la intertextualidad como lectura crítica y como intervención en una herencia cultural. Con frecuencia, esta intervención inicia preguntándose por los vacíos y silencios en los relatos mitológicos o históricos, como en los poemas que reconstruyen la perspectiva de la Señora Midas o de la esposa de Shakespeare, Anne Hathaway, de quien se conocen sólo unos pocos datos además de su mención en el testamento del poeta. En otros casos, la labor de estas voces poéticas es desmentir o rectificar la forma sesgada en que se ha narrado la historia: así lo expresa Mrs Beast: "These myths going round, these legends, fairytales / I'll put them straight" (Duffy, 1999: 72). Eurídice, como veremos enseguida, tiene un objetivo similar.

Ovidio es parte fundamental de la tradición que The World's Wife pretende reinterpretar: en esta colección, los poemas inspirados por las Metamorfosis incluyen, además de "Eurydice", "Medusa", "Mrs Tiresias", "Pygmalion's Bride", "Mrs Sisyphus" y "Demeter". El discurso de estas mujeres puede expresar ternura y añoranza, pero el tono predominante en la colección "is often tough, slangy, sexy, and crude" (Harries, 2015: 161). Este tono puede encontrarse en un poema temprano en la carrera de Duffy, que también se ocupa de cuestionar las dinámicas de poder implicadas en los actos de mirar y representar. En "Standing Female Nude", publicado en 1985, la voz poética es una trabajadora sexual que posa para un pintor de vanguardia. Su actitud hacia el artista que pretende inmovilizarla y confinarla al espacio del cuadro es irreverente y escéptica: ella está consciente de que tanto el pintor como los futuros espectadores no ven en ella una persona, sino un cuerpo segmentado y sexualizado ("Belly nipple arse in the window light"), un objeto a someter, evaluar y poseer: "I shall be represented analytically and hung / in great museums. The bourgeoisie will coo / at such an image of a river-whore. They call it Art" (Duffy, 2016: 44). Al final, ella se deslinda del retrato, declara "It does not look like me" (Duffy, 2016: 44), y de esta manera escapa de la estaticidad de una representación objetificante.

Al igual que "Standing Female Nude", "Eurydice" es un poema enunciado por una mujer que consigue eludir la mirada de un artista posesivo. En él, Orfeo se presenta como "an all-too recognisable type of the contemporary career-poet, vain, fallible and insecure" (Wainwright, 2003: 51). El tono de "Eurydice", como veremos, es muy diferente al de Retrato de una mujer en llamas, y como advierte Wainwright (2003), "any consideration of [these poems] needs to keep in mind the lightsome satirical tone that dominates The World's Wife" (47). Este uso del humor no sólo conduce a una aproximación irreverente a la construcción mítica de personajes como Darwin, Fausto, Freud, Odiseo o Shakespeare: la presencia de mujeres comediantes es algo que Duffy ha continuado explorando en sus libros posteriores, ya que reírse de los discursos hegemónicos puede servir para comenzar a desactivarlos — la modelo de "Standing 
Female Nude" dice "It makes me laugh" y "These artists / take themselves too seriously" (Duffy, 2016: 44).

"Eurydice" es un monólogo, como el resto de los poemas de la colección, y su dimensión performativa es aún más evidente desde la apóstrofe en el primer verso: "Girls" es el término que Eurídice usa para llamar a su audiencia, y más adelante les ordena: "Girls, forget what you've read / It happened like this" (Duffy, 1999: 61). Aunque hay frustración y enojo en el discurso de Eurídice, es una de las voces en la colección que más recuerda a una stand-up comedian: la risa subversiva no es en este caso la risa de la voz poética, sino la de su audiencia dentro y fuera del texto. La primera estrofa establece la perfecta compatibilidad entre Eurídice, quien sólo desea paz y silencio, y su residencia permanente en el inframundo:

I was dead and down

in the Underworld, a shade,

a shadow of my former self, nowhen.

It was a place where language stopped,

a black full stop, a black hole

where words had to come to an end.

And end they did there,

last words,

famous or not.

It suited me down to the ground. (Duffy, 1999: 58)

Para Eurídice, esta quietud en el reino de los muertos ha sido una solución extrema para librarse de Orfeo. No se aclara si fue el suicidio lo que la trajo aquí (buscando deliberadamente ser herida por la serpiente), pero el inframundo parece ser el único sitio en el que cierto poeta que la llamaba "His Muse" y no paraba de abrumarla con versos al fin la ha dejado en paz. En consecuencia, Eurídice observa, horrorizada, cómo el inframundo le da la bienvenida a Orfeo: "Just picture my face / when I heard - / Ye Gods - / a familiar knock-knock-knock at Death's door" (Duffy, 1999: 58). Orfeo irrumpe "With his lyre / and a poem to pitch, with me as the prize" (Duffy, 1999: 59). Esta alusión al concurso de poesía deriva en una crítica hacia la institución que ha celebrado el genio de Orfeo, a pesar de que sus poemas reducen a la mujer deseada a figuras bidimensionales como "Dearest, Beloved, Dark Lady, White Goddess" (Duffy, 1999: 59) y termina por perpetuar una narrativa sesgada y distorsionada, con contraportadas que exageran y falsean los poderes del canto del poeta: 
The blurb on the back of his books claimed

that animals, aardvark to zebra,

flocked to his side when he sang,

fish leapt in their shoals

at the sound of his voice,

even the mute, sullen stones at his feet

wept wee, silver tears.

Bollocks. (I'd done all the typing myself,

I should know.)

$[\ldots]$

But the Gods are like publishers,

usually male,

and what you doubtless know of my tale

is the deal. (Duffy, 1999: 59)

Después de este pasaje, que alude a cómo la participación activa de las mujeres en hacer posibles las grandes obras literarias suele pasar desapercibida, el poema de Duffy vuelve a seguir de cerca el relato ovidiano, describiendo el momento en el que el inframundo se detiene para atender la petición de Orfeo, y el reino entero de Hades queda cautivado por su canción. Incrédula, Eurídice es testigo de cómo la demanda de Orfeo es concedida y los deseos y opiniones de ella son ignorados. De momento, no parece haber un punto de reconciliación, ya que se sugiere que la subordinación de Eurídice está codificada en el mismo lenguaje y en las convenciones representacionales. Ella prefiere el silencio al canto porque su experiencia le ha mostrado que la lírica sólo tiene un lugar para ella en la medida que encarne un ideal de belleza y feminidad que alimente la inspiración del poeta. Parecería una respuesta directa a la pregunta retórica del texto de Ovidio, "what, then, could she complain of, except that she had been loved?": el amor posesivo y egoísta de Orfeo es precisamente lo que ha llevado a Eurídice a preferir el inframundo:

Like it or not,

I must follow him back to our life -

Eurydice, Orpheus' wife -

to be trapped in his images, metaphors, similes,

octaves and sextets, quatrains and couplets,

elegies, limericks, villanelles, histories, myths . . (Duffy, 1999: 60) 
Al ser "wife" una identidad tan central en la colección, es llamativo que aquí esta palabra rima con "life", pues son los dos estados que Eurídice rechaza: ser esposa y estar viva. Su recelo hacia las formas cerradas, las predilectas de Orfeo, también se refleja en su discurso: en este monólogo, los patrones rítmicos y de repetición dependen más bien de la aliteración y de las enumeraciones. Siguiendo la trama del mito, Eurídice comienza el ascenso hacia el mundo de los vivos, marchando detrás de Orfeo, quien tiene prohibido voltear a verla. Ella le ruega que le permita quedarse, pero Orfeo la ignora por completo, una imagen de indiferencia que resulta muy distinta del poeta cuya sensibilidad fue capaz de conmover hasta las lágrimas a las mismas Furias:

Girls, forget what you've read.

It happened like this -

I did everything in my power to make him look back. [...]

I stretched out my hand

to touch him once

on the back of his neck.

Please let me stay.

But already the light had saddened from purple to grey. (Duffy, 1999: 61)

De acuerdo con el relato de Ovidio, Orfeo gira para ver a Eurídice porque no resiste la incertidumbre de no saber si ella está siguiéndolo. Pero la prohibición de Hades no incluía que Eurídice no pudiera tocarlo o hablarle; por lo tanto, aquí Orfeo sabe con certeza que Eurídice sí se encuentra detrás de él. Ya que en esta versión Orfeo no tiene el impulso de corroborar que el pacto con Hades se ha cumplido, ella tiene que pensar en otra forma de hacerlo voltear. Su idea genial consiste en aprovechar la vanidad del poeta:

My voice shook when I spoke -

Orpheus, your poem's a masterpiece.

I'd love to hear it again...

He was smiling modestly

when he turned,

when he turned and he looked at me.

What else?

I noticed he hadn't shaved.

I waved once and was gone. (Duffy, 1999: 61-62) 
A pesar de su importante labor de subversión de los mitos y los relatos históricos, y de su visibilización de cómo serían estas narrativas si se centraran en el punto de vista de las mujeres que acompañaron a los héroes, The World's Wife no se propone considerar estas voces de manera completamente autónoma, sin referencia a la presencia masculina. Una excepción sería el último poema, "Demeter", que se enfoca en la restauración del vínculo madre-hija. Esta diferencia en la forma de revisión de los mitos empieza a asemejarse al modo en el que Retrato de una mujer en llamas revive el mito de Eurídice y Orfeo. Sciamma pretende explorar los efectos del orden patriarcal en las vidas de las mujeres, pero sin que éstas interactúen con hombres durante gran parte de la película. Las palabras pronunciadas por los pocos personajes masculinos son contadas, y ninguno de ellos tiene nombre: "when [men] do appear, they often have their backs turned or their faces out of focus; when we finally do see a man's face clearly, it feels like an intrusion” (Syme, 2020: s. p.).

\section{"Vous pensez qu'elle a voulu mourir?"}

Una preocupación central en Retrato de una mujer en llamas son las decisiones que una creadora toma en el acto de representar y las convenciones que sigue, voluntaria o inconscientemente. Los primeros segundos de la película muestran las manos de diferentes mujeres comenzando un boceto. Estos pares de manos pertenecen a varias estudiantes de arte, y cuando sus rostros aparecen, se vuelve claro que todas ellas están mirando hacia el mismo punto, hacia una modelo. Pero esta modelo es también la profesora, Marianne, quien se encuentra en control de la clase y del proceso de representación. Ella dicta instrucciones a las alumnas: les ordena mirarla con suficiente detenimiento, prestar atención a la posición de sus brazos y a sus manos. De este modo, la película comienza a construir un argumento sobre cómo posar no es un acto pasivo: el método enseñado por Marianne sugiere que una modelo puede establecer los términos bajo los que desea ser representada. No obstante, en el primer tercio de la película este deseo de control sobre la propia imagen se manifiesta más bien como una negativa a posar. La película relata a modo de analepsis la experiencia de Marianne años atrás, cuando aceptó retratar a Héloïse, una mujer joven perteneciente a la clase aristocrática. Para llegar a la casa en la que pintará el retrato, Marianne viaja en un pequeño bote - aquí inician los paralelismos con el mito ovidiano, pues para llegar al reino de los muertos también se necesitaba cruzar en una embarcación- $-{ }^{2}$ En la película no vuelve

2 El texto de Ovidio (2000) dice, en traducción de A. S. Kline: "[Orpheus] dared to go down to Styx, through the gate of Taenarus, also, to see if he might not move the dead” (s. p.). Después de romper el pacto al ver a Eurídice, Orfeo intenta sin éxito volver a cruzar la laguna. 
a aparecer un hombre sino hasta los últimos minutos, cuando uno de los marineros viene a embalar el cuadro terminado y a recoger a Marianne. Durante su primer día en la casa donde trabajará, Marianne descubre que Héloïse vivía hasta hace poco en un convento, pero tuvo que dejarlo y volver con premura a su casa después de la muerte de su hermana mayor, prometida en matrimonio a un caballero milanés; esto significa que ahora Héloïse debe tomar su lugar. Marianne interroga a Sophie, la criada, quien fue la única testigo de la muerte de la hermana mayor: Sophie está convencida de que ella tomó la decisión de morir saltando de un acantilado — ha llegado a esta conclusión porque la mujer no gritó al caer-. Este salto voluntario hacia la muerte, con el objetivo de evitar un matrimonio forzado, coincide con la Eurídice de Duffy.

Marianne recibe el encargo del retrato porque éste será enviado como regalo al pretendiente de Héloïse, y así se asegurará su aprobación antes de que la boda se lleve a cabo. Esta situación origina un conflicto: la complicidad de la artista en la mercantilización de otras mujeres. Al entrar a la casa de la familia de Héloïse, un imponente retrato de la madre de esta última recibe a los visitantes. Marianne reconoce el cuadro como obra de su padre, y la madre de Héloïse, la Condesa, recuerda cómo esta imagen fue también usada para pactar su matrimonio: "Ce portrait est arrivé ici avant moi. Quand je suis entrée dans cette pièce pour la première fois, je me suis retrouvée face à mon image, accrochée au mur. Elle m'attendait" (Sciamma, 2019: 00:16:11). La Condesa se refiere a su propia imagen en tercera persona, "elle", reconociendo la pérdida de la identidad que también experimentó, y a la que el artista contribuyó por medio del acto de representación. El problema de no reconocerse o no identificarse con un retrato será central más adelante para la rebelión de Héloïse. Asimismo, este uso de la tercera persona recuerda la afirmación de la modelo de "Standing Female Nude": "It does not look like me" (Duffy, 2016: 44).

El aprendizaje de Marianne de los códigos y las convenciones representacionales en el estudio de su padre ha significado absorber también un modo de mirar: "she inherits not only [her father's] trade as a painter but also the male gaze inherent within his art" (Gan, 2020: s. p.). Ya que Héloïse rechaza el compromiso con el noble milanés, ha elegido protestar de una forma efectiva: el artista anterior a Marianne renunció, frustrado, porque no logró que Héloïse posara para él. La Condesa pide a la pintora que aparente ser una compañera de paseos, y que observe a Héloïse: su labor será entonces no sólo de retratista, sino también de vigilante, anticipando que Héloïse podría estar considerando tomar la misma decisión que su hermana.

El retrato que el pintor previo dejó inconcluso ha quedado abandonado en la sala que se acondiciona como habitación y estudio para Marianne: el efecto ominoso de un cuerpo sin rostro, y más adelante un vestido sin nadie que lo porte, son parte de una serie de "trampas" con las que la película posterga el primer encuentro con Héloïse: no 
la vemos sino hasta el momento en que Marianne lo hace. Durante sus paseos juntas, Marianne comprende que la vida en el convento ofrecía a Héloïse una sensación de equidad que no existirá en su matrimonio: más aún, el confinamiento en la casa materna la ha privado de dos de las cosas que la hacen más feliz: escuchar música y tener acceso a libros. Sin que Héloïse lo advierta, Marianne debe observar y memorizar los rasgos de su compañera de paseos, para después trabajar en el retrato en secreto. Este primer tercio de la película se concentra en las implicaciones éticas de mirar sin que la mirada sea recíproca. El trabajo en secreto evoca el telar de Penélope, un personaje a quien Duffy también da voz en The World's Wife. Marianne debe ocultar sus manos manchadas de óleos para evitar las sospechas de Héloïse, con quien cada vez siente mayor afinidad. Para crear el retrato, Marianne debe observar a la modelo con disimulo y de manera fragmentaria, realizando rápidos estudios de las manos, el perfil o las orejas de Héloïse sin que ella se dé cuenta. Pero, una vez más siguiendo la lógica de "Standing Female Nude", esta representación que trata a la modelo como partes segmentadas será pronunciada fallida.

La mañana en la que el cuadro debe ser entregado y enviado a Milán, Marianne elige confesar la verdad a Héloïse. Esta última rechaza el cuadro (véase Figura 1) y confronta a la pintora: "Vous me voyez comme ça?" (Sciamma, 2019: 00:49:27). Consciente de que ha perpetuado los mecanismos que objetifican y desposeen a la mujer hacia quien siente solidaridad y atracción, Marianne daña el cuadro irreparablemente. La Condesa, a punto de salir de viaje, acepta concederle a la pintora cinco días más para pintar un nuevo retrato, pero esta vez Héloïse declara que está dispuesta a posar.

Durante estos cinco días, las tres mujeres jóvenes se acercan aún más: una noche, Héloïse lee en voz alta un fragmento del libro x de Metamorfosis en el que se narra el mito de Eurídice y Orfeo. Sophie responde con indignación al error de Orfeo, pues las reglas eran suficientemente claras, y le enfurece que Eurídice deba pagar las consecuencias. En cambio, Marianne cree entender los motivos de Orfeo. Su acción no se explica por un impulso irracional, sino que tuvo una elección ante sí: "Il choisit le souvenir d'Eurydice. C'est pour ça qu'il se retourne. Il ne fait pas le choix de l'amoureux. Il fait le choix du poète" (Sciamma, 2019: 01:13:44). Héloïse termina de leer el episodio y reflexiona: "Peut-être que c'est elle qui lui a dit 'retourne-toi"” (Sciamma, 2019: 1:14:16). Esta escena anticipa los destinos de ambas: Marianne tendrá que escoger la representación (la elección de la poeta), y será Héloïse quien incite a Marianne a mirar atrás, no sólo en el sentido literal, sino también al mirar al pasado - recordemos que la película inicia en una época posterior de la vida de Marianne.

Aunque al confesar la verdad sobre el primer cuadro Marianne intenta justificar el resultado aludiendo a convenciones, reglas y estructuras que rigen los actos de representación individuales, durante las sesiones que ambas comparten estas convenciones 


\section{Figura 1}

El primer retrato, realizado en secreto y sin el consentimiento de Héloïse

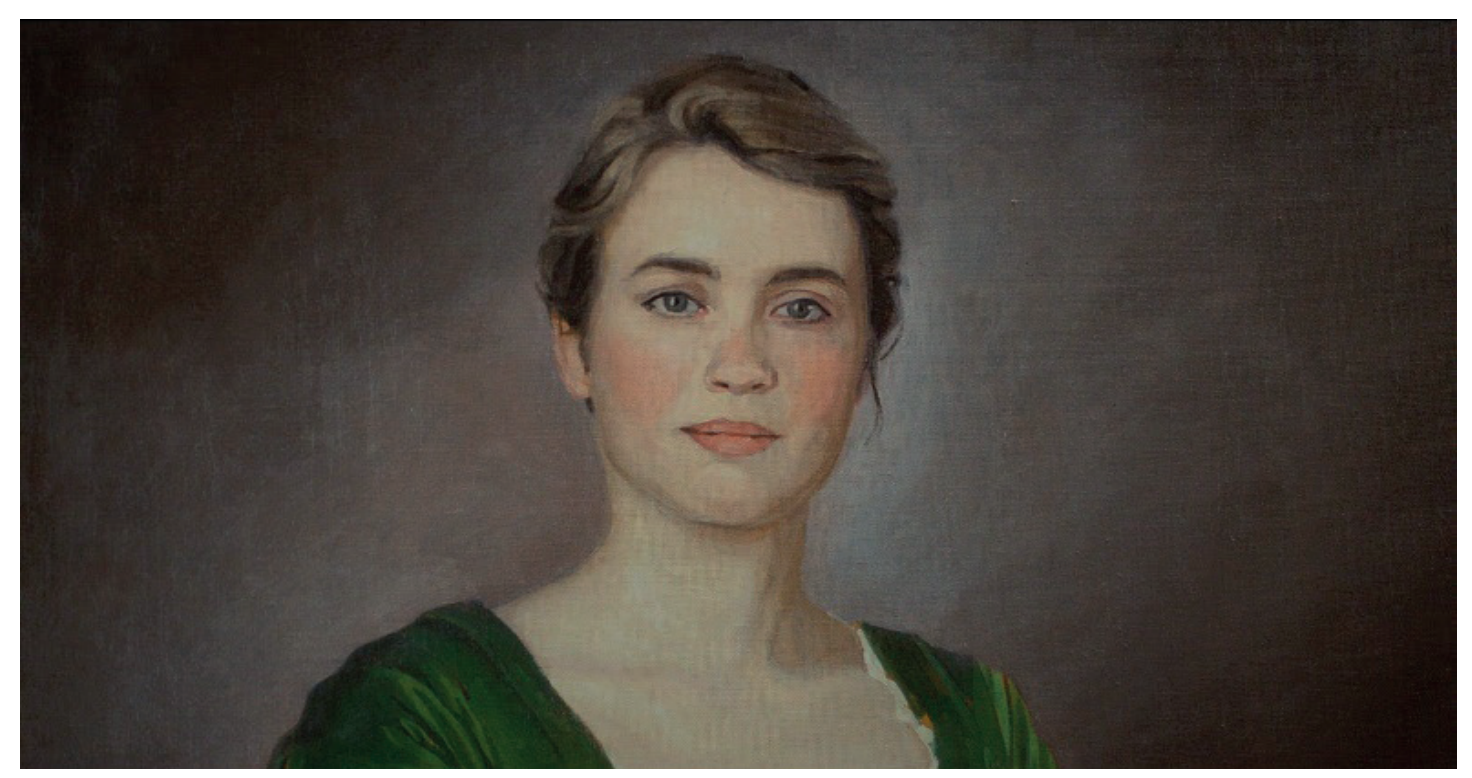

Fuente: Sciamma (2019: 00:48:52)

ahora se reescriben, o se retoman, con ironía. ${ }^{3}$ Por ejemplo, Marianne recita algunas de las frases que suele decirles a las modelos: "Vous avez un teint remarquable aujourd'hui. Vous êtes très élégant. Posez à merveille. Vous êtes jolie" (Sciamma, 2019: 01:09:10). Pero Héloïse no se toma en serio estas palabras, pues percibe lo que hay detrás de estas barreras, como si el escudo que el caballete representa hubiera dejado de proteger a Marianne. Sin embargo, la mirada masculina que Marianne ha internalizado no desaparece de un momento a otro: Héloïse acusa a Marianne de pintar con su futuro esposo en mente, y más adelante le demuestra que el acto de mirar es recíproco, que ella también ha estado observando y memorizando a Marianne desde que se conocieron. Aunque Marianne tiene la libertad de viajar y trabajar, Héloïse insiste en que, al menos durante las sesiones de retrato, "Nous sommes dans la même place [...] Si vous me regardez, qui je regarde moi?" (Sciamma, 2019: 01:04:42). Cuando Marianne da las pinceladas finales al segundo cuadro (ver Figura 2), ambas mujeres están del lado del caballete que corresponde a la retratista, casi como si firmaran la obra juntas. Marianne y Héloïse ahora pueden mirarse en términos equitativos, o mirar juntas hacia la misma dirección.

\footnotetext{
3 En sus diálogos también surge la idea de cómo las mujeres son controladas no sólo mediante imágenes que las representan como propiedades o como seres dóciles, sino también al limitar lo que tienen permitido ver: en el siglo XVIII estaba prohibido que las pintoras vieran a modelos masculinos desnudos. Más que una cuestión de recato, aclara Marianne, al obstaculizar el estudio de la anatomía masculina se les impide a las artistas contribuir a los grandes temas de la pintura (Sciamma, 2019: 01:08:09).
} 


\section{Figura 2}

El segundo retrato, con Héloïse como modelo y coautora

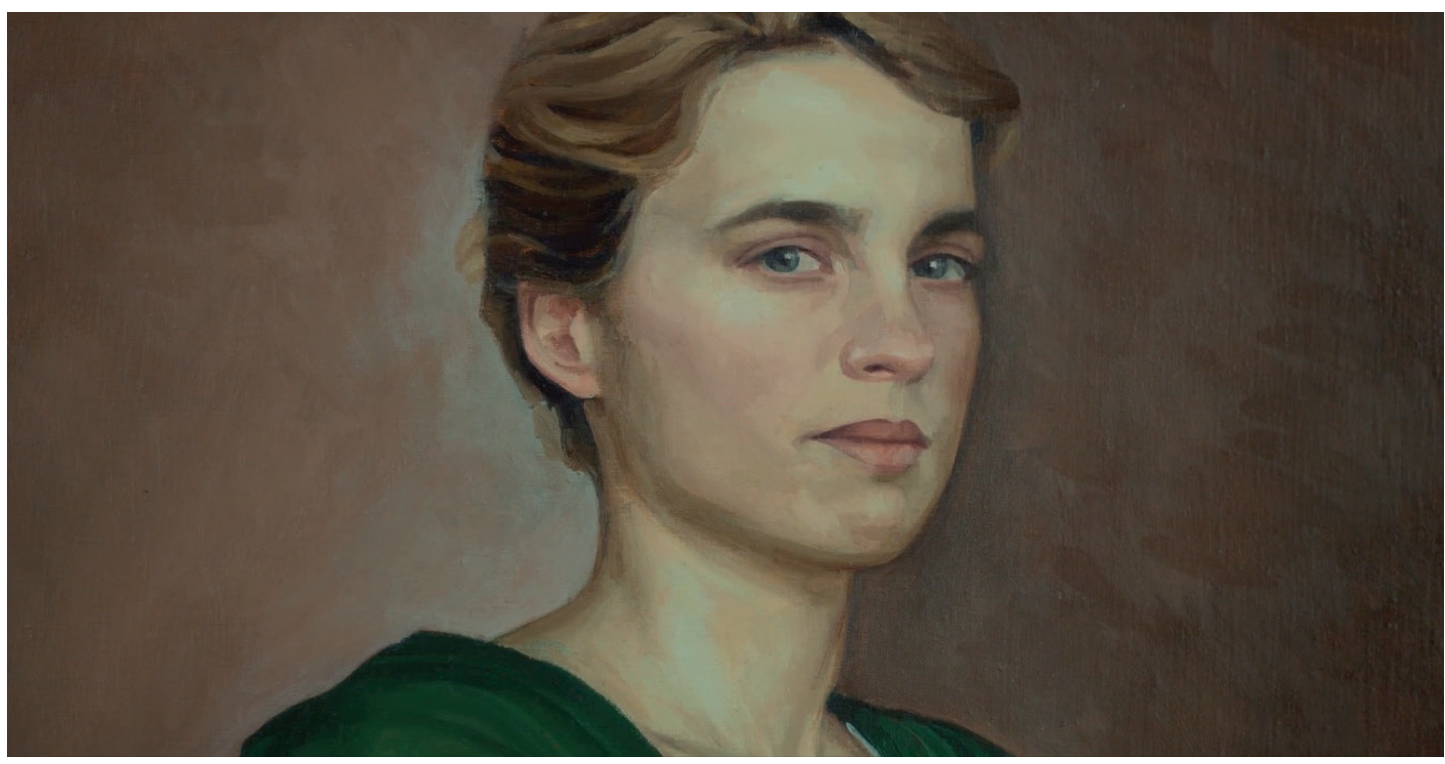

Fuente: Sciamma (2019: 01:42:07)

Cuando Héloïse posa, Marianne deja de usar su delantal de pintora, y de esta forma ambas son observadoras y co-creadoras. Retomando la distinción que propone Richardson (2016), Marianne entiende que sólo podrá pintar a Héloïse si su "gaze" da paso a un "look", y con ello a una relación más horizontal.

La tragedia de Marianne es que no puede evitar ser cómplice de entregar a Héloïse a un hombre poderoso: lo único que puede hacer es representar a su amada bajo términos consensuados. Cumplir con el trabajo para el que fue contratada significa que ella hace posible la partida de Héloïse, y por eso llega a expresar su deseo de destruir también el segundo retrato: "par lui, je vous donne à un autre" (Sciamma, 2019: 01:36:00). El conocimiento de que la separación será inevitable cuando el cuadro sea entregado se relaciona con las visiones o premoniciones que comienzan a acechar a Marianne: en dos momentos de la película, ella camina sola por los pasillos y las escaleras de la casa, y al darse la vuelta ve una aparición de Héloïse en un vestido de novia. No queda claro si estas apariciones son alucinaciones, presagios, o si los recuerdos se han contaminado con la última imagen que Marianne tuvo de Héloïse antes de perderla. Cuando Marianne tiene que irse, Héloïse la persigue hasta la puerta y la llama, utilizando por primera vez el pronombre "tu" en lugar de "vous": "Retourne-toi!" (Sciamma, 2019: 01:51:17). Como Orfeo en el poema de Duffy, Marianne se da la vuelta y ve a la Héloïse real en su vestido de novia. Enseguida, la puerta se cierra y la imagen de Héloïse se oscurece. Al girar, Marianne acepta esta visión como una forma de hacer eterna a su amada en la 
única forma posible: mediante un retrato. Un día antes de despedirse, Marianne había hecho una versión en miniatura del retrato para el que Héloïse posó, un acto que vuelve tangible la idea de que una representación sustituye o viene en lugar de alguien ausente. Marianne también hace un autorretrato para Héloïse en el libro de Ovidio. Con el tiempo, reconoce Héloïse refiriéndose a la miniatura, "c'est elle que vous verrez, quand vous penserez à moi” (Sciamma, 2019: 01:42:47).

Aunque el prometido de Héloïse sólo recibirá un retrato, hasta este punto el público ha visto cinco: el cuadro inconcluso del primer artista, los dos retratos "públicos" hechos por Marianne, y estos dos retratos privados. Al contrastar todos estos actos de representación, Retrato de una mujer en llamas sugiere que la creación de imágenes siempre ocurre en el marco de estructuras de poder más amplias, y que esto es algo ante lo que la cineasta y sus colaboradoras eligen posicionarse. Sobre esto, Jones (2003) comenta: "visual images not only narrativize power relations $[\ldots]$ but bear these relations within their very formal structure and in their conditions of distribution" (3); esta lectura permite entender el cuadro no sólo como un elemento de la trama, sino como la materialización de una labor autorreflexiva que atraviesa los actos de representación ficcionales y extratextuales.

El tema de Eurídice y Orfeo tiene un impacto duradero en la obra de Marianne: de vuelta en el presente, ella expone en una galería (aunque debe hacerlo bajo el nombre de su padre) un cuadro que representa el momento en que Orfeo mira hacia atrás y Eurídice se hunde de nuevo en el mundo de los muertos. Uno de los asistentes a la exposición comenta la posición inusual en la que se encuentra la pareja: el cuadro sugiere una despedida mutua. El vestido blanco de Eurídice sin duda se parece al vestido de novia de Héloïse, mientras que la túnica de Orfeo es del mismo tono de azul que el vestido que Marianne lleva en esta escena (véase Figura 3). Si la casa representa el inframundo que Marianne visita brevemente y debe abandonar sola, resulta notorio que la película de Sciamma hace un uso muy limitado de la música: el entorno de Eurídice es un mundo silencioso. El fondo de las conversaciones entre Marianne y Héloïse suele ser el sonido del mar, y sólo se escucha música cuando las tres jóvenes asisten a una reunión en torno a una fogata con otras mujeres del pueblo, cuando Marianne toca los primeros compases del tercer movimiento de El verano de Vivaldi, y al final de la película, cuando esta pieza se escucha en una sala de conciertos.

Como señala C. J. Gan (2020), expresiones como "hauntingly beautiful", que son comunes en reseñas de Retrato de una mujer en llamas, si bien pueden parecer un lugar común, apuntan a una idea central de la película: la forma en la que los vivos son acechados por quien ya no está y por lo que ya no es (en cierto modo, las visiones de Marianne sí hacen pensar en una casa embrujada): "when we speak of haunting, we evoke the figure of the ghost, the specter of the dead, or, put another way, the presence 


\section{Figura 3}

Marianne en la galería con su cuadro de Eurídice y Orfeo

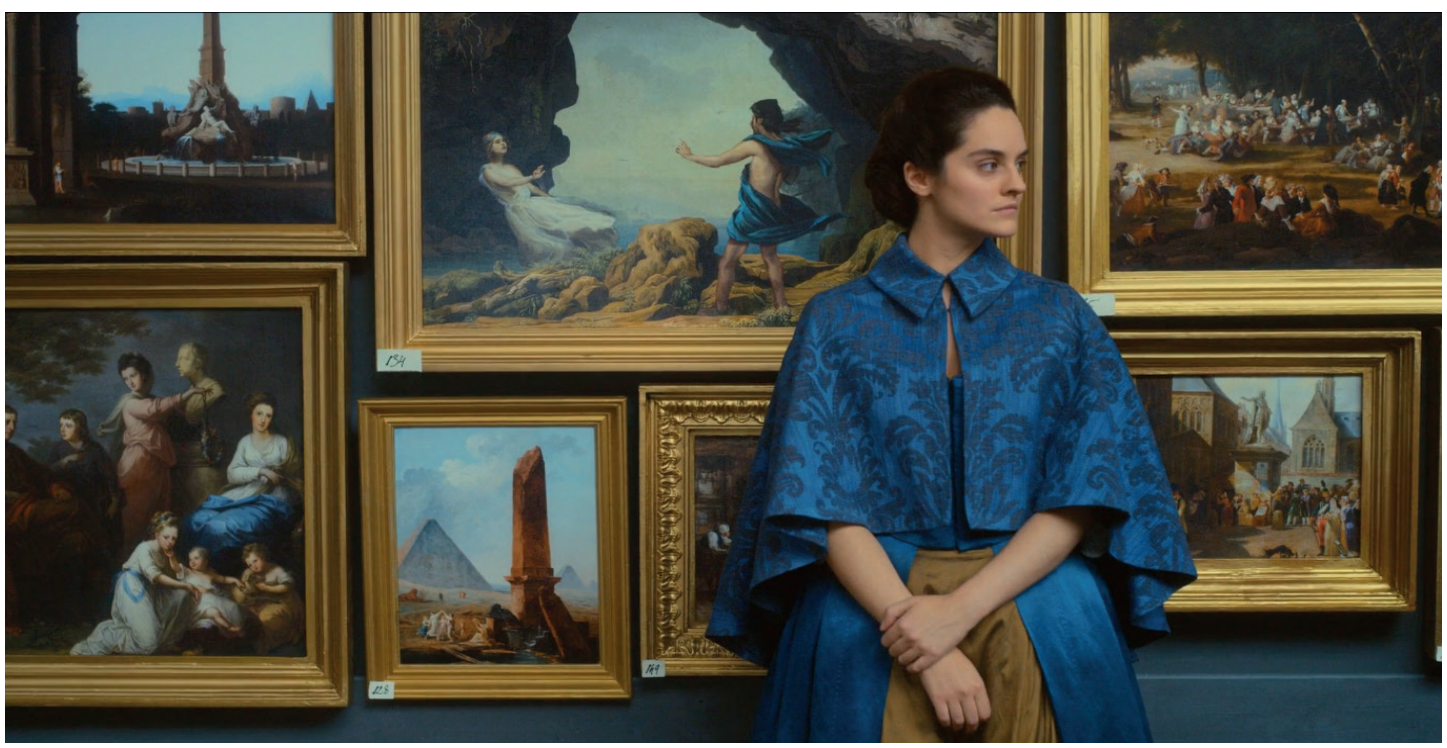

Fuente: Sciamma (2019: 01:52:36)

of an absence - something gone but not quite disappeared that lingers on" (s. p.). Marianne repetirá la elección de la poeta, pintando a Héloïse en el cuadro que da título a la película, pero sin volver a cruzar la mirada con la Héloïse real.

\section{Conclusiones: "Nous sommes à la même place. Exactement la même place"}

En "Standing Female Nude", Carol Ann Duffy describía la asimetría del acto de representar en términos de posesión sexual: lo que sugieren obras como "Eurydice" y Retrato de una mujer en llamas es que una mirada posesiva y narcisista no puede ser el fundamento de una historia de amor. Sciamma afirma que "the movie is fully about consent and how consent is also super erotic and super sexy" (citada en VanDerWerff, 2020: s. p.). Si extendemos esta idea a la relación entre erotismo y representación, es claro que esta última también debe ser un acto consensuado. Por otra parte, a Duffy no le resultaría ajeno este estudio de cómo la amante sobrevive en la memoria, ya que su propia colección de poesía Rapture (2005) analiza el carácter cíclico de revivir la historia de una relación amorosa mediante el lenguaje, y también adapta un modo de enunciación canónico (el soneto) para hablar del deseo entre mujeres. El soneto "Art", situado casi al final de Rapture, reúne los temas de las artes visuales como una eternidad 
alternativa ante el final de la relación amorosa, y la música como fuerza emotiva ligada a la memoria:

Only art now - our bodies, brushstroke, pigment, motif;

our story, figment, suspension of disbelief;

the thrum of our blood, percussion;

chords, minor, for the music of our grief. (Duffy, 2005: 60)

Este poema habla de espacios vacíos habitados por espectros, en forma similar a la lectura de Gan (2020) que enlaza a Eurídice con el fantasma de Héloïse: "huge theatres for the echoes that we left" (Duffy, 2005: 60). Pero creo que Rapture apunta a una conclusión más optimista: ahora la intervención de Duffy en el canon va más allá de un cambio de perspectiva, ya que logra apropiarse del modo lírico y hacer que el célebre instrumento musical cambie de manos: ahora será usado para enunciar el deseo femenino entre iguales, y el poeta más celebrado de la antigüedad ya no será Orfeo, sino Safo. Del mismo modo, Céline Sciamma no concibe la cámara cinematográfica como un instrumento de objetificación que privilegie al espectador masculino heterosexual, sino que reconoce la aportación de todo un equipo de mujeres que hacen posible una obra colaborativa, al mismo tiempo que imagina una historia de amor queer que pudo haber ocurrido en una época distante.

"Vous pensez que tous les amants ont le sentiment d'inventer quelque chose?", pregunta Héloïse (Sciamma, 2019: 01:23:38). La respuesta de Retrato de una mujer en llamas sería que las experiencias retratadas en la película no son nuevas, pero esta forma de mirarlas sí lo es. Estas reescrituras permiten el ascenso a la superficie de historias y perspectivas ocultas bajo el modo convencional de mirar. En contraste con el silencio y la penumbra del inframundo, la voz y la mirada de Eurídice pueden ofrecer un comentario necesario a la realidad viva.

\section{Referencias bibliográficas}

Beard, Mary. (2014, 20 de marzo). "The Public Voice of Women". The London Review of Books, 36(6). Recuperado el 3 de octubre de 2020 de https://www.lrb.co.uk/the-paper/ v36/n06/mary-beard/the-public-voice-of-women

Duffy, Carol Ann. (1999). The World's Wife. Londres: Picador.

DufFy, Carol Ann. (2005). Rapture. Nueva York: Faber and Faber. 
DufFy, Carol Ann. (2016 [1985]). Standing Female Nude. Londres: Picador.

Gan, C. J. (2020, 13 de marzo). "Haunted Paintings: The Female Ghost in Portrait of a Lady on Fire" (en línea). The College Hill Independent. Recuperado el 10 de octubre de 2020 de http://www.theindy.org/1963

H. D. (1916). "Eurydice” (en línea). Poetry Foundation. Recuperado el 13 de octubre de $2020 \mathrm{de}$ https://www.poetryfoundation.org/poems/51869/eurydice-56d22fe6d049d

HARries, Elizabeth Wanning. (2015). "Changing the Story: Fairy Tale, Fantasy, Myth". En Mary Eagleton y Emma Parker (eds.), The History of British Women's Writing, 1970-Present, Volume Ten. Londres: Palgrave Macmillan. 158-169.

JONES, Amelia. (2003). "Introduction: Conceiving the intersection of feminism and visual culture". En Amelia Jones (ed.), The Feminism and Visual Culture Reader. Londres: Routledge. 1-8.

Loizeaux, Elizabeth Bergmann. (2008). Twentieth-Century Poetry and the Visual Arts. Cambridge: Cambridge University Press.

Mitchell, W. J. T. (2005). What Do Pictures Want? The Lives and Loves of Images. Chicago: University of Chicago Press.

Ovidio. (2000). Metamorphoses (A. S. Kline, trad.) [en línea]. Recuperado el 2 de octubre de 2020 de https://ovid.lib.virginia.edu/trans/Ovhome.htm

Richardson, Niall. (2016 [2010]). Transgressive Bodies: Representations in Film and Popular Culture. Nueva York: Routledge.

Russ, Joanna. (1995 [1972]). "What Can a Heroine do? Or Why Women Can’t Write”. En Joanna Russ, To Write Like a Woman: Essays in Feminism and Science Fiction. Bloomington: Indiana University Press. 79-93.

Sciamma, Céline (directora). (2019). Portrait de la jeune fille en feu [Retrato de una mujer en llamas] [cinta cinematográfica]. Lilies Films.

Syme, Rachel. (2020, 4 de marzo). "“Portrait of a Lady on Fire' Is More Than a 'Manifesto on the Female Gaze"'. The New Yorker. Recuperado el 2 de octubre de 2020 de https://www. 
newyorker.com/culture/cultural-comment/portrait-of-a-lady-on-fire-is-more-than-a$\underline{\text { manifesto-on-the-female-gaze }}$

TIFF TALKs. (2019, 6 de septiembre). Portrait of a Lady on Fire Cast and Crew Q\&A|TIFF 2019 [Archivo de video]. YouTube. https://youtu.be/88L8pIEr1nk

VAnDerWerff, Emily. (2020, 19 de febrero). "Portrait of a Lady on Fire director Céline Sciamma on Her Ravishing Romantic Masterpiece" (en línea). Vox. Recuperado el 12 de octubre de 2020 de https://www.vox.com/culture/2020/2/19/21137213/portrait-of-a-ladyon-fire-celine-sciamma-interview

Wainwright, Jeffrey. (2003). "Female Metamorphoses: Carol Ann Duffy's Ovid". En Angelica Michelis y Antony Rowland (eds.), Choosing Tough Words: The Poetry of Carol Ann Duffy. Manchester: Manchester University Press. 47-55. 